\title{
Cardiomyopathy in Pregnancy with COVID-19: An Enigma
}

Shraddha Ashok Mevada ${ }^{1}$, Madhuri Alap Mehendale ${ }^{2}$, Arun Harishchandra Nayak ${ }^{3}$, Priyanka Murlidhar Gite ${ }^{4}$, Nadiya Saeed Khan ${ }^{5}$

\begin{abstract}
Background: The coronavirus disease-2019 (COVID-19), caused by severe acute respiratory syndrome coronavirus 2 (SARS-CoV-2), is a global public health emergency. Physiological and mechanical changes in pregnancy increase susceptibility to infections in general, particularly when the cardiorespiratory system is affected, and encourage rapid progression to respiratory and heart failure in the gravida.

Case description: We present a case report of 30-year-old primigravidae with 36.5 weeks by date and 37 week by scan with diagnosed preeclampsia 2 weeks back on medication with $11 \times 10.4 \times 10.9 \mathrm{~cm}$ single intramural anterior wall fibroid with breech presentation. COVID nasopharyngeal sample reported as SARS-CoV-2 real-time PCR positive. The patient was started on medication defining the Stage 1 Group A Asymptomatic Category. Chest X-ray showed mild bilateral pulmonary infiltrates. On Day 6 of admission, the patient went in labor, and hence was taken for emergency LSCS in view of primigravidae with breech with preeclampsia with fibroid with PROM under spinal anesthesia with all precautions. Intraoperatively, the LSCS was uneventful. Postoperatively 6 hours postpartum, the patient developed sudden onset breathlessness NYHA Grade 4, with saturation of 56\%, and patient was intubated and shifted to ICU. Chest X-ray revealed viral pneumonia, and further 2D ECHO was suggestive of cardiomyopathy.

Conclusion: We suggest an echocardiogram in pregnant women with coronavirus disease 2019 pneumonia, in particular those necessitating oxygen or those who are critically ill.

Clinical significance: Viral myocarditis and cardiomyopathy have been reported in nonpregnant COVID-19 patients. Information on COVID-19 in pregnancy is currently limited. No specific literature is available of viral cardiomyopathy reported in pregnant women with COVID-19 infection. Keywords: Cesarean section, Fibroid, Preeclampsia.

Journal of South Asian Federation of Obstetrics and Gynaecology (2020): 10.5005/jp-journals-10006-1810
\end{abstract}

\section{BACKGROUND}

Coronavirus disease-2019 (COVID-19), caused by severe acute respiratory syndrome coronavirus 2 (SARS-CoV-2), is a worldwide public health emergency. Pregnant women are high-risk population during infectious disease outbreaks. Physiological changes in pregnancy increase susceptibility to infections in general. Furthermore, we know that the normal pregnancy bias toward T-helper 2 (Th2) system dominance, which is helpful to the fetus but makes the mother susceptible to viral infections, which are more effectively contained by the Thelper 1 system. ${ }^{1}$ Changes in various systems in pregnancy increase a woman's susceptibility to infection and hypoxic compromise but also delay diagnosis and source control in those with only innocuous respiratory tract symptoms such as sore throat and nasal congestion. As per the data, it states that shortness of breath is seen in 18\% of patients with COVID-19.

As we know, physiologic dyspnea is common in pregnancy and must be distinguished from pathologic breathlessness. Also, functional residual capacity and end-residual volumes keep on decreasing from early pregnancy due to diaphragmatic splinting by the gravid uterus, which results in reduced total lung capacity at term and an difficulty to clear pulmonary secretions effectively.

We know that COVID-19 pneumonia can present from focal to diffuse consolidation of lung parenchyma, which would predispose to hypoxemic respiratory failure in pregnancy. As per the recent literature, viral myocarditis and cardiomyopathy have been documented in nonpregnant COVID-19 patients. ${ }^{2,3}$ Data on COVID19 in pregnancy is currently very limited. ${ }^{3-5}$ No specific literature is available about COVID-19 viral cardiomyopathy in pregnancy.
${ }^{1-5}$ Department of Obstetrics and Gynecology, Lokmanya Tilak Muncipal Medical College and General Hospital, Mumbai, Maharashtra, India

Corresponding Author: Madhuri Alap Mehendale, Department of Obstetrics and Gynecology, Lokmanya Tilak Muncipal Medical College and General Hospital, Mumbai, Maharashtra, India, Phone: +91 9769363190, e-mail: drmadhuri1982@yahoo.co.in

How to cite this article: Mevada SA, Mehendale MA, Nayak AH, et al. Cardiomyopathy in Pregnancy with COVID-19: An Enigma. J South Asian Feder Obst Gynae 2020;12(4):243-244.

Source of support: Nil

Conflict of interest: None

\section{Case Description}

We present a case report of 30-year-old primigravidae with 36.5 weeks by date and 37 week by scan with diagnosed preeclampsia 2 weeks back on medication with $11 \times 10.4 \times 10.9 \mathrm{~cm}$ single intramural anterior wall fibroid with breech presentation. COVID nasopharyngeal sample reported as SARS-CoV-2 real-time PCR positive. The patient was started on medication defining the Stage 1 Group A Asymptomatic Category. Ultrasonography report was suggestive of Single Live Intrauterine Gestation with breech presentation with 36 week 6 days with estimated fetal weight of $2488 \mathrm{~g}$. A large $11 \times 10.4 \times 10.9 \mathrm{~cm}$ single intramural anterior wall fibroid with vascularity noted.

Investigations were as follows:

CBC-Hemoglobin: $10 \mathrm{~g} \%$, TLC: $15,800 / \mathrm{mm}^{3}$, platelet count: 3.48 lac

(-) The Author(s). 2020 Open Access This article is distributed under the terms of the Creative Commons Attribution 4.0 International License (https://creativecommons. org/licenses/by-nc/4.0/), which permits unrestricted use, distribution, and non-commercial reproduction in any medium, provided you give appropriate credit to the original author(s) and the source, provide a link to the Creative Commons license, and indicate if changes were made. The Creative Commons Public Domain Dedication waiver (http://creativecommons.org/publicdomain/zero/1.0/) applies to the data made available in this article, unless otherwise stated. 


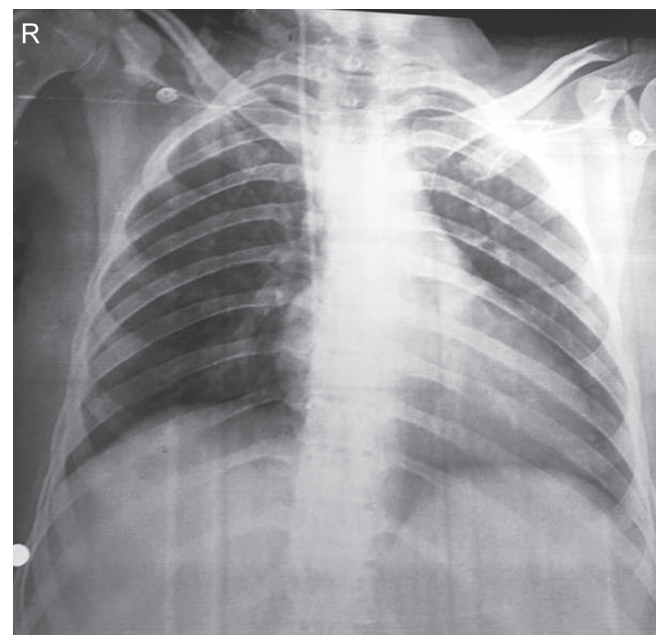

Fig. 1: Mild bilateral lung infiltrates preoperatively

Liver test and renal test were with normal limit.

Coagulation profile is normal. Chest $\mathrm{X}$-ray was done suggestive of mild bilateral lung infiltrates as shown in Figure 1.

On day 6 of admission, emergency LSCS was taken in view of primigravidae with breech with preeclampsia with fibroid with premature rupture of membranes. Intraoperative findings: a large anterior wall intramural fibroid $13 \times 12 \times 10 \mathrm{~cm}$ was noted $2 \mathrm{~cm}$ just above Kerr's incision. Baby was delivered by breech presentation, $B C I A B$ with APGAR 1 minutes and 5 minutes as 9/10. Rest of the surgery was uneventful. Postoperatively the patient was monitored strictly. However, 6 hours postpartum, the patient developed sudden onset of breathlessness, NYHA Grade 4, Tachypnea (RR;40/ minute) with Spo2-60\% on O2, tachycardia (PR-110/minute), and patient was intubated and shifted to ICU. Chest X-ray revealed viral pneumonia with bilateral infiltrates as shown in Figure 2. Investigation showed elevated troponin and CRP levels. Bedside 2D ECHO was suggestive of Global left ventricular hypokinesia, ejection fraction $25-30 \%$, mild mitral regurgitation, mild tricuspid regurgitation, dilated chambers, mild pericardial effusion, No pulmonary artery hypertension, and no clots. Patient recovered well and was tested SARS-CoV-2 real-time PCR negative Day 9 of LSCS. The patient improved symptomatically and was discharged on day 10.

\section{Discussion}

We are still unaware whether the incidence of developing COVID-19 cardiomyopathy is more in the pregnant population or it is similar to the rate in nonpregnant patients. As we know, pregnancy is a state of compensated respiratory alkalosis with metabolic acidosis which makes pregnant population vulnerable to respiratory diseases such as COVID-19.

Although tachypnea and shortness of breath are not always unique findings to COVID-19 infection or cardiomyopathy in pregnant COVID-19 woman, performing an echocardiogram should be considered to evaluate for cardiomyopathy.

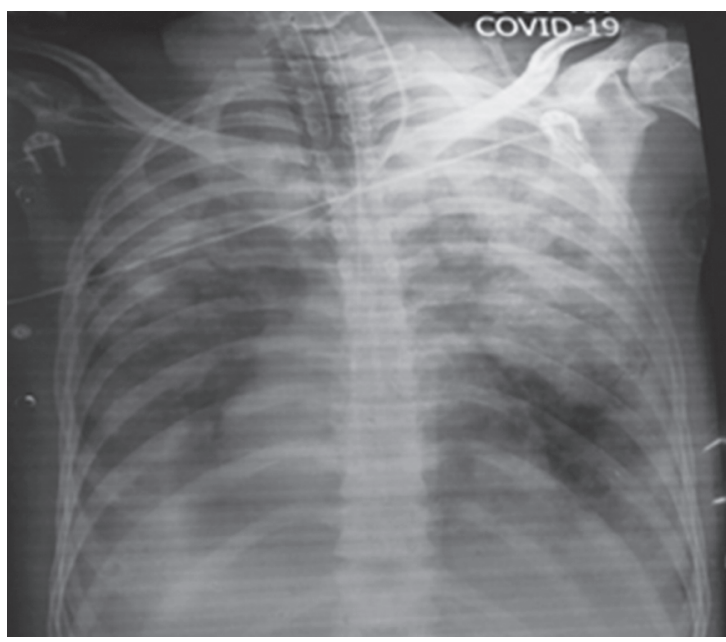

Fig. 2: Viral pneumonia with cardiomyopathy postoperatively

In our case, the differential diagnosis was either PPCM (post-partum cardiomyopathy) or viral cardiomyopathy. Definitive diagnostic test to differentiate between PPCM and viral cardiomyopathy would be cardiac MRI and cardiac tissue biopsy, which would be difficult to perform on all cases, hence challenging issue.

\section{Clinical Significance}

The literature shows incidence of viral myocarditis and cardiomyopathy in nonpregnant COVID-19 patients. Data on COVID19 in pregnancy is currently very limited. No specific literature is yet available on cardiomyopathy due to coronavirus reported in pregnant women with COVID-19 infection

\section{Ethical Statement}

Ethical principles were maintained throughout the case and consent of the patient was taken in local language.

\section{References}

1. Naccasha N, Gervasi MT, Chaiworapongsa T. Phenotypic and metabolic characteristics of monocytes andgranulocytes in normal pregnancy and maternal infection. Am J Obstet Gynecol 2001;185(5):1118-1123. DOI: 10.1067/mob.2001.117682.

2. Guo T, Fan $Y$, Chen $M$, et al. Cardiovascular implications of fatal outcomes of patients with coronavirus disease 2019 (COVID-19). JAMA Cardiol 2020;5(7):811-818. DOI: 10.1001/jamacardio.2020.1017.

3. Arentz M, Yim E, Klaff L, et al. Characteristics and outcomes of 21 critically ill patients with COVID-19 in Washington State. JAMA 2020;323(16):1612-1614. DOI: 10.1001/jama.2020.4326.

4. Di Mascio D, Khalil A, Saccone G, et al. Outcome of coronavirus spectrum infections (SARS, MERS, COVID-19) during pregnancy: a systematic review and meta-analysis. Am J Obstet Gynecol MFM 2020;2(2):100107. DOI: 10.1016/j.ajogmf.2020.100107.

5. Breslin N, Baptiste C, Miller R, et al. Coronavirus disease 2019 in pregnancy: early lessons. Am J Obstet Gynecol MFM 2020;2(2):100111. DOI: 10.1016/j.ajogmf.2020.100111. 